\title{
Avaliação das curvas de secagem de guaco (Mikania glomerata Spreng.) em secador de bandejas
}

RADÜNZ, L.L.'; MELO, E.C².; ROCHA, R.P. ${ }^{*}$; BARBOSA, F.F. ${ }^{3}$; SANTOS, R.H.S.2; BERBET, P.A4. 'Universidade Federal da Fronteira Sul, CEP 89812-000, Chapecó-Brasil ${ }^{2}$ Universidade Federal de Viçosa, CEP 36570-000, Viçosa-MG, Brasil. *ronicely.rocha@ufv.br ${ }^{3}$ Universidade Federal de Pelotas, CEP 96010610, Pelotas-Brasil ${ }^{4}$ Universidade Estadual do Norte Fluminense, CEP 28013-602, Goytacazes-Brasil

\begin{abstract}
RESUMO: Esse trabalho teve como objetivo avaliar diferentes modelos matemáticos para determinar a curva de secagem de guaco. Para a condução do experimento, foi utilizado um secador com ventilação forçada, com 4 bandejas, empregando gás liquefeito de petróleo como fonte de aquecimento. Foram realizados 6 tratamentos de secagem: com ar aquecido a 40, 50, 60,70 e $80^{\circ} \mathrm{C}$, e com ar a temperatura ambiente. Para todos os tratamentos a velocidade do ar de secagem passando através da massa de plantas foi mantida em, aproximadamente, 0,5 $\mathrm{m} \mathrm{s}^{-1}$. Para ajuste dos modelos matemáticos aos dados experimentais realizou-se análise de regressão não-linear pelo método Quasi-Newton empregando-se o programa computacional STATISTICA 6.0 ${ }^{\circledR}$, sendo os valores dos parâmetros dos modelos estimados em função da temperatura do ar de secagem. Apenas o modelo proposto por Midilli et al. apresentou ajuste satisfatório para descrever o processo de secagem de guaco, independentemente da temperatura do ar de secagem, enquanto o modelo da aproximação da difusão se adequou para a temperatura ambiente e com ar aquecido a $60^{\circ} \mathrm{C}$.
\end{abstract}

Palavras-chave: Plantas medicinais, modelos matemáticos, cinética de secagem

ABSTRACT: Evaluation of drying curves of Mikania glomerata Spreng. in a tray dryer. This work aimed to evaluate different mathematical models to determine the curve of the drying of Mikania glomerata Spreng. . For the conduction of the experiment, a drier with forced ventilation was used, with 4 trays, using liquefied petroleum gas as heating source. Six drying treatments were carried out, that is, with hot air at $40,50,60,70$ and $80^{\circ} \mathrm{C}$, as well as drying with air at room temperature. For all the treatments, the drying air speed, through the mass of plants, were kept at, approximately, $0.5 \mathrm{~m} \mathrm{~s}^{-1}$. For the adjustment of the mathematical models to the experimental data, nonlinear regression analysis was performed through the Quasi-Newton method, using the computational program STATISTICA 6.0 ${ }^{\circledR}$, and the values of the parameters of the models were estimated in function of the temperature of the drying air. But only the model considered by Midilli et al. presented satisfactory adjustment to describe the process of drying Mikania glomerata Spreng., regardless of the temperature of the drying air, while the model of diffusion approximation was suitable for room temperature and hot air at $60^{\circ} \mathrm{C}$.

Keywords: Medicinal plants, mathematical models, drying kinetics

\section{INTRODUÇÃO}

O guaco (Mikania glomerata Spreng.), pertencente à família Asteraceae, é uma planta nativa da América do Sul, perene, trepadeira, com caule volúvel; ramos lenhosos, cilíndricos, castanhos e glabros; folhas opostas, pecioladas, cordiformedeltóides, membranáceas, glabras, de margem lisa, e de cor verde; inflorescência em capítulos sésseis, reunidos em glomérulos globosos ou oblongos, no ápice dos ramos; flores brancacentas e fruto tipo aquênio. Popularmente, com fins medicinais, a planta é empregada, principalmente, como broncodilatador e expectorante, sendo útil em afecções do aparelho respiratório (gripe, tosse, ronqueira, bronquite e asma). Também empregado em reumatismos, nevralgias e como sudorífero, febrífugo, depurativo e cicatrizante (Low et al., 1999). Apesar de possuir várias indicações terapêuticas populares, somente a ação broncodilatadora, antitussígena, expectorante e edematogênica sobre as vias respiratórias foram comprovadas (Oliveira et al., 1998). 
Bolina et al. (2009) realizaram a prospecção fitoquímica de folhas de guaco (Mikania glomerata), obtido de extratos etanólicos. Constataram a presença da cumarina (1,2-benzopirona), triterpenos, esteróides e heterosídeos flavônicos no extrato etanólico. O teor de cumarina encontrado foi de $0,30 \pm 0,01 \%$.

Estimativas feitas a respeito do mercado mundial de produtos farmacêuticos afirmam que, do montante de US\$320 bilhões comercializados por ano, US\$ 20 bilhões são originados de substâncias ativas derivadas de plantas (Robbers et al., citados por Guerra \& Nodari, 2003), estando de acordo com Wilke (2003). O mercado brasileiro de fitoterápicos movimenta aproximadamente US\$ 400 milhões ao ano, conforme dados da Associação Brasileira das Empresas do Setor Fitoterápico (Abifisa, 2003). Ainda segundo o estudo, o faturamento previsto para 2010 foi superior a US\$ 1 bilhão.

Nas espécies medicinais, a secagem é uma operação unitária de preparação para o armazenamento, a fim de atender as necessidades da indústria farmacêutica de fitoterápicos, que não tem estrutura para usar as plantas frescas nas quantidades exigidas para a produção industrial (Lorenzi \& Matos, 2002).

O método de secagem, a velocidade e temperatura do ar exercem influência na quantidade e qualidade dos princípios ativos, presentes em plantas medicinais, aromáticas e condimentares (Melo et al., 2004), ou seja, pode ocorrer aumento ou redução do teor do princípio ativo.

De acordo com Resende et al. (2008), as curvas de secagem variam com a espécie, variedade, condições ambientais, métodos de preparo pós-colheita, entre outros fatores. Nesse sentido, diversos modelos matemáticos têm sido utilizados para descrever o processo de secagem de produtos agrícolas.

Existem três tipos de modelos de secagem usados para descrever a cinética de secagem de produtos agrícolas. O modelo teórico, que considera apenas a resistência interna a transferência de calor e água entre o produto $\mathrm{e} o$ ar quente, os modelos semi-teóricos e os empíricos, que consideraram somente a resistência externa a temperatura e umidade relativa do ar de secagem (Midilli et al., 2002; Panchariya et al., 2002).

A modelagem matemática do sistema de secagem de plantas medicinais e aromáticas possibilita analisar e determinar o comportamento do sistema dinâmico do secador, procurando preservar as características naturais das plantas e buscar uma alta eficiência durante a secagem (Prates et al., 2007).

Rao et al. (2001) secaram cardamomogigante (Amomum subulatum Roxburgh) com ar aquecido a 70,82 e $90^{\circ} \mathrm{C}$ e vazão do ar de secagem de $0,46,0,58$ e $0,69 \mathrm{~m}^{3} \mathrm{~min}^{-1}$, e observaram que a declividade da curva de secagem foi constante para um determinado tempo de secagem e então decresceu, indicando duas regiões de secagem, ou seja, o período de taxa constante e o período de taxa decrescente de secagem.

Portanto, o objetivo do trabalho foi de realizar a secagem de guaco, em secador de bandejas, submetido a diferentes temperaturas de secagem e ajustar os dados experimentais a diversos modelos matemáticos.

\section{MATERIAL E MÉTODO}

Para execução do experimento foi utilizada a planta medicinal conhecida popularmente por guaco (Mikania glomerata Spreng.), cultivada numa área experimental da Universidade Federal de Viçosa-MG. O cultivo foi realizado em uma área homogênea, a pleno sol, no sistema de espaldeira, sendo a nutrição realizada apenas com uso de adubações orgânicas (esterco).

O experimento montado para a condução do processo de secagem baseou-se em delineamento de blocos casualizados, sendo constituído por três blocos. Os tratamentos de secagem foram: temperatura ambiente (média de $21,44^{\circ} \mathrm{C}$ e desvio padrão de 1,76) e ar aquecido a 40, 50, 60, 70 e $80^{\circ} \mathrm{C}$, todos com variação de $\pm 1^{\circ} \mathrm{C}$.

Foram coletadas apenas as folhas, no horário compreendido entre as 7:00 e 8:30 horas, e o material encaminhado imediatamente ao Laboratório de Secagem para seleção, determinação do teor de água e posterior secagem. As folhas foram selecionadas antes da secagem, retirando-se as partes doentes e danificadas, assim como qualquer parte de outro vegetal ou material estranho que pudesse se encontrar presente e, em seguida 0 material foi homogeneizado.

O teor de água foi determinado imediatamente após a coleta e, ao final do processo de secagem, empregando o método gravimétrico. Optou-se pela metodologia recomendada pela Asae Standards (Asae, 2000) para forrageiras e similares (plantas ou folhas), utilizando-se $25 \mathrm{~g}$ de amostra, em três repetições, em estufa com circulação forçada do ar e com temperatura de $103 \pm 2^{\circ} \mathrm{C}$, durante 24 horas.

Para condução do experimento de secagem utilizou-se um secador de bandejas, a gás, com controle automático de temperatura, segundo Radünz (2004). A câmara de secagem era composta por cinco bandejas quadrangulares, com tampas teladas, construídas de aço inoxidável, com as dimensões $0,25 \mathrm{~m}$ de lado e $0,15 \mathrm{~m}$ de altura, conforme demonstrado nas Figura 1. 


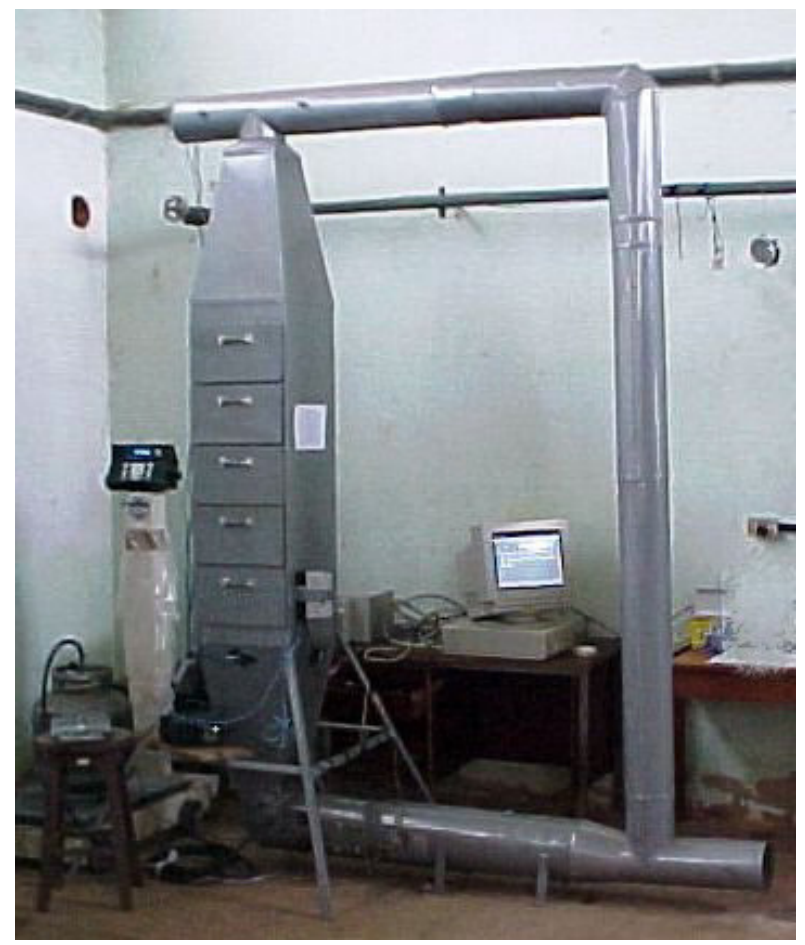

FIGURA 1. Vista frontal do secador.

Para calcular a umidade de equilíbrio, foi utilizado o modelo proposto por Corrêa et al. (2002) para esta espécie, conforme apresentado na equação 1.

$$
\mathrm{Ue}=\frac{1}{\mathrm{a} \cdot \mathrm{T} \cdot \mathrm{bUR} \mathrm{R}} \quad \text { Equação } 1
$$

\section{Sendo:}

Ue= umidade de equilíbrio (b.s.);

$\mathrm{T}=$ temperatura do $\operatorname{ar}\left({ }^{\circ} \mathrm{C}\right)$;

UR= umidade relativa do ar na câmara de secagem (decimal); e

$a, b, c=$ parâmetros que dependem da natureza do produto.

A razão de umidade ( $R U$ ) do produto foi calculada para o tempo t, conforme apresentado na equação 2.

$$
R U=\frac{U_{x}-U_{e}}{U_{0}-U_{e}}
$$

\section{Sendo:}

$\mathrm{RU}=$ razão de umidade (adimensional);

$U \mathrm{x}=$ teor de água do produto no tempo $\mathrm{x}$ (b.s.);

Ue= umidade de equilíbrio (b.s.); e

$\mathrm{U}_{0}=$ teor de água inicial do produto (b.s.).

As folhas foram secadas sem picar (inteiras), utilizando-se apenas duas bandejas do secador, a segunda e a terceira ascendente, sem estarem completamente cheias, totalizando uma massa de $0,5 \mathrm{~kg}$, em virtude do material disponível.

urante a secagem, a obtenção dos dados referentes à temperatura do ar ambiente, do ar de secagem, do ar de exaustão e do ar na massa do produto, e da umidade relativa do ar ambiente, do ar de secagem e do ar de exaustão, foi realizada por um sistema automático de aquisição de dados, utilizando-se termopares tipo $\mathrm{T}$, previamente calibrados. A medição da velocidade do ar de secagem foi realizada utilizando-se anemômetro de pás, com faixa de operação de 0 a $30 \mathrm{~m} \mathrm{~s}^{-1} \mathrm{e}$ sensibilidade de $0,01 \mathrm{~m} \mathrm{~s}^{-1}$.

Os valores observados, para cada temperatura do ar de secagem, foram ajustados a 8 diferentes modelos matemáticos, conforme apresentado na Tabela 1.

Para o ajuste dos modelos matemáticos aos dados experimentais, realizou-se análise de regressão não-linear, pelo método QuasiNewton, empregando-se o programa computacional Statistica $6.0^{\circledR}$, sendo os valores dos parâmetros dos modelos, estimados em função da temperatura do ar de secagem.

A escolha modelo foi realizada em função do coeficiente de determinação ajustado $\left(R^{2}\right)$, do erro médio relativo (EMR), do erro médio estimado (EME) e pela análise dos resíduos.

O erro médio relativo e o erro médio

TABELA 1. Modelos matemáticos avaliados para descrever a secagem de guaco.

\begin{tabular}{ll}
\hline Modelo & Equação \\
\hline Dois termos & $R U=a^{*} \exp \left(-k^{*} t\right)+b^{*} \exp \left(-q^{*} t\right)$ \\
Aproximação da difusão & $R U=a^{*} \exp \left(-k^{*} t\right)+(1-a)^{*} \exp \left(-k^{*} b^{*} t\right)$ \\
Exponencial de dois termos & $R U=a^{*} \exp \left(-k^{*} t\right)+(1-a)^{*} \exp \left(-k^{*} a^{*} t\right)$ \\
Henderson e Pabis & $R U=a^{*} \exp \left(-k^{*} t\right)$ \\
Henderson e Pabis modificada & $R U=a^{*} \exp \left(-k^{*} t\right)+b^{*} \exp \left(-q^{*} t\right)+c^{*} \exp \left(-w^{*} t\right)$ \\
Lewis & $R U=\exp \left(-k^{*} t\right)$ \\
Midilli et al. & $R U=a^{*} \exp \left(-k^{*} t n\right)+b^{*} t$ \\
Page & $R U=\exp \left(-k^{*} t\right)^{n}$ \\
\hline
\end{tabular}


estimado, para cada modelo, foram calculados pelas equações 3 e 4, respectivamente.

$$
\begin{aligned}
& \mathrm{ERM}=\frac{100}{\mathrm{n}} \sum \frac{\left|\mathrm{Y}-\mathrm{Y}_{0}\right|}{\mathrm{Y}} \quad \text { Equação } 3 \\
& \mathrm{EME}=\sqrt{\frac{\sum\left(\mathrm{Y}-\mathrm{Y}_{0}\right)^{2}}{\mathrm{GLM}}} \quad \text { Equação } 4 \\
& \text { Sendo: } \\
& \text { n= número de observações; } \\
& \mathrm{Y}=\text { valor observado; } \\
& \mathrm{YO}=\text { valor estimado pelo modelo; e } \\
& \text { GLM= graus de liberdade do modelo. }
\end{aligned}
$$

\section{RESULTADOS E DISCUSSÂO}

Os valores da umidade de equilíbrio, calculados através do modelo proposto por Corrêa et al. (2002), foram 16,14\%; 8,37\%, 5,93\%; 4,52\%; $3,73 \%$ e $3,25 \%$ b.s., respectivamente, para a secagem com ar ambiente e com ar aquecido a 40, $50,60,70$ e $80^{\circ} \mathrm{C}$.

Os valores da velocidade do ar de secagem, verificados sobre as bandejas de secagem, foram de $0,59 \pm 0,049 \mathrm{~m} \mathrm{~s}^{-1} ; 0,45 \pm 0,029 \mathrm{~m} \mathrm{~s}^{-1} ; 0,46 \pm 0,046 \mathrm{~m} \mathrm{~s}^{-1}$; $0,46 \pm 0,022 \mathrm{~m} \mathrm{~s}^{-1} ; 0,45 \pm 0,042 \mathrm{~m} \mathrm{~s}^{-1} ; 0,44 \pm 0,022 \mathrm{~m} \mathrm{~s}^{-1}$;

\begin{tabular}{|c|c|c|c|c|}
\hline Modelo matemático & Temperatura $\left({ }^{\circ} \mathrm{C}\right)$ & $\mathbf{r}^{2}$ & EMR (\%) & EME \\
\hline \multirow{6}{*}{ Dois termos } & Ambiente $(21,5)$ & 0,9970 & 30,71 & 0,051 \\
\hline & 40 & 0,9926 & 52,40 & 0,117 \\
\hline & 50 & 0,9951 & 50,81 & 0,059 \\
\hline & 60 & 0,9956 & 40,59 & 0,047 \\
\hline & 70 & 0,9953 & 35,32 & 0,046 \\
\hline & 80 & 0,9926 & 68,97 & 0,056 \\
\hline \multirow{6}{*}{ Aproximação da difusão } & Ambiente $(21,5)$ & 0,9987 & 9,34 & 0,039 \\
\hline & 40 & 0,9931 & 52,37 & 0,130 \\
\hline & 50 & 0,9991 & 19,83 & 0,029 \\
\hline & 60 & 0,9997 & 10,38 & 0,015 \\
\hline & 70 & 0,9990 & 15,47 & 0,025 \\
\hline & 80 & 0,9996 & 20,60 & 0,015 \\
\hline \multirow{6}{*}{ Exponencial de dois termos } & Ambiente $(21,5)$ & 0,9968 & 33,64 & 0,075 \\
\hline & 40 & 0,9925 & 50,42 & 0,166 \\
\hline & 50 & 0,9940 & 57,64 & 0,094 \\
\hline & 60 & 0,9949 & 44,38 & 0,071 \\
\hline & 70 & 0,9949 & 37,20 & 0,067 \\
\hline & 80 & 0,9918 & 72,61 & 0,084 \\
\hline \multirow{6}{*}{ Henderson e Pabis } & Ambiente $(21,5)$ & 0,9970 & 30,76 & 0,073 \\
\hline & 40 & 0,9926 & 50,94 & 0,164 \\
\hline & 50 & 0,9951 & 50,79 & 0,084 \\
\hline & 60 & 0,9956 & 40,59 & 0,066 \\
\hline & 70 & 0,9953 & 35,32 & 0,064 \\
\hline & 80 & 0,9926 & 68,97 & 0,079 \\
\hline \multirow{6}{*}{ Henderson e Pabis modificada } & Ambiente $(21,5)$ & 0,9970 & 30,76 & 0,042 \\
\hline & 40 & 0,9926 & 51,21 & 0,095 \\
\hline & 50 & 0,9951 & 50,79 & 0,048 \\
\hline & 60 & 0,9956 & 40,59 & 0,038 \\
\hline & 70 & 0,9953 & 35,32 & 0,037 \\
\hline & 80 & 0,9926 & 68,97 & 0,046 \\
\hline
\end{tabular}
respectivamente, para secagem com ar ambiente e com ar aquecido a 40,50, 60, 70 e $80^{\circ} \mathrm{C}$.

$\mathrm{Na}$ Tabela 2 são apresentados os valores dos coeficientes de determinação ajustados $\left(R^{2}\right)$, dos

TABELA 2. Valores dos coeficientes de determinação ajustados $\left(R^{2}\right)$, dos erros médios relativos (EMR) e dos erros médios estimados (EME), para os modelos matemáticos avaliados 
TABELA 2. Valores dos coeficientes de determinação ajustados $\left(R^{2}\right)$, dos erros médios relativos (EMR) e dos erros médios estimados (EME), para os modelos matemáticos avaliados

\begin{tabular}{ccccc} 
& & & & continuação... \\
& Ambiente $(21,5)$ & 0,9968 & 33,98 & 0,106 \\
& 40 & 0,9906 & 44,61 & 0,262 \\
Lewis & 50 & 0,9941 & 56,97 & 0,131 \\
& 60 & 0,9950 & 43,79 & 0,099 \\
& 70 & 0,9949 & 37,20 & 0,095 \\
& 80 & 0,9919 & 72,15 & 0,117 \\
\hline \multirow{3}{*}{ Midilli et al. } & Ambiente $(21,5)$ & 0,9986 & 10,43 & 0,035 \\
& 40 & 0,9983 & 13,99 & 0,055 \\
& 50 & 0,9995 & 10,44 & 0,020 \\
& 60 & 0,9998 & 6,85 & 0,010 \\
& 70 & 0,9995 & 6,94 & 0,014 \\
& 80 & 0,9997 & 13,30 & 0,012 \\
\hline \multirow{2}{*}{ Page } & Ambiente $(21,5)$ & 0,9968 & 33,62 & 0,075 \\
& 40 & 0,9906 & 44,61 & 0,185 \\
& 50 & 0,9941 & 56,97 & 0,092 \\
& 60 & 0,9950 & 43,79 & 0,070 \\
& 70 & 0,9949 & 37,20 & 0,067 \\
& 80 & 0,9919 & 72,15 & 0,083 \\
\hline
\end{tabular}

erros médios relativos (EMR) e dos erros médios estimados (EME), para cada um dos modelos matemáticos avaliados.

Conforme observado na Tabela 2, o coeficiente de determinação ajustado $\left(r^{2}\right)$ apresentou resultados superiores a 0,99 , independentemente do modelo e da temperatura do ar de secagem. Entretanto, observando os valores do erro médio relativo, apenas o modelo proposto por Midilli et al. apresentou ajuste adequado para descrever 0 processo de secagem de guaco, independentemente da temperatura do ar de secagem, enquanto que o modelo da aproximação da difusão se ajustou apenas para a temperatura ambiente e com ar aquecido a $60^{\circ} \mathrm{C}$. Isto porque o modelo de Midilli et al. apresenta os menores valores percentuais de erro médio, com valores inferiores ou ligeiramente superiores a $10 \%$, o que indica, de acordo com Mohapatra \& Rao (2005), serem adequados à descrição deste fenômeno.

Além dos valores do coeficiente de determinação e do erro médio relativo, também foram calculados os valores do erro médio estimado (Tabela 2) e, observa-se que os menores valores foram encontrados para o modelo de Midilli et al., dentre todos os testados e para todas as temperaturas testadas. Segundo Draper e Smith (1998), a fidelidade de modelo em descrever determinado processo físico é inversamente proporcional ao valor do erro médio relativo. Dessa forma, quanto menor for o valor deste erro, melhor será a qualidade de ajuste do modelo em relação aos dados observados.

Nas figuras 2 a 13 estão demonstrados as curvas de secagem e os respectivos resíduos, obtidos dos dados observados e pelos valores simulados apenas para a equação de Midilli et al., para folhas de guaco seca a diferentes temperaturas para o ar de secagem.

Observa-se pelos gráficos de resíduos que a distribuição foi aleatória, exceto para o tratamento de secagem com ar aquecido para $40^{\circ} \mathrm{C}$, onde a distribuição foi tendenciosa. Porém, a amplitude dos resíduos foi muito pequena, possibilitando que o modelo estime valores muito próximo aos observados. Para todas as demais temperaturas de secagem o modelo de Midilli et al. apresentou valores de resíduos distribuídos aleatoriamente.

Assim, baseado nos resultados estatísticos supracitados, indica-se o modelo de Midilli et al. para descrever o processo de secagem de folhas de guaco. Também, Martinazzo et al. (2007) secando folhas de capim limão, Radünz et al. (2011) secando carqueja, Prates et al. (2012) secando folhas de fruta-de-lobo, Evin (2012) utilizando Gundelia tourneforti L., e Reis et al. (2012) utilizando folhas de manjericão concluíram que o modelo de Midilli foi o que melhor se ajustou aos dados experimentais de secagem.

Quanto ao tempo de secagem, observa-se que para o tempo foi inversamente proporcional a temperatura do ar de secagem, conforme esperado. As curvas de secagem apresentaram comportamentos semelhantes para todas as 


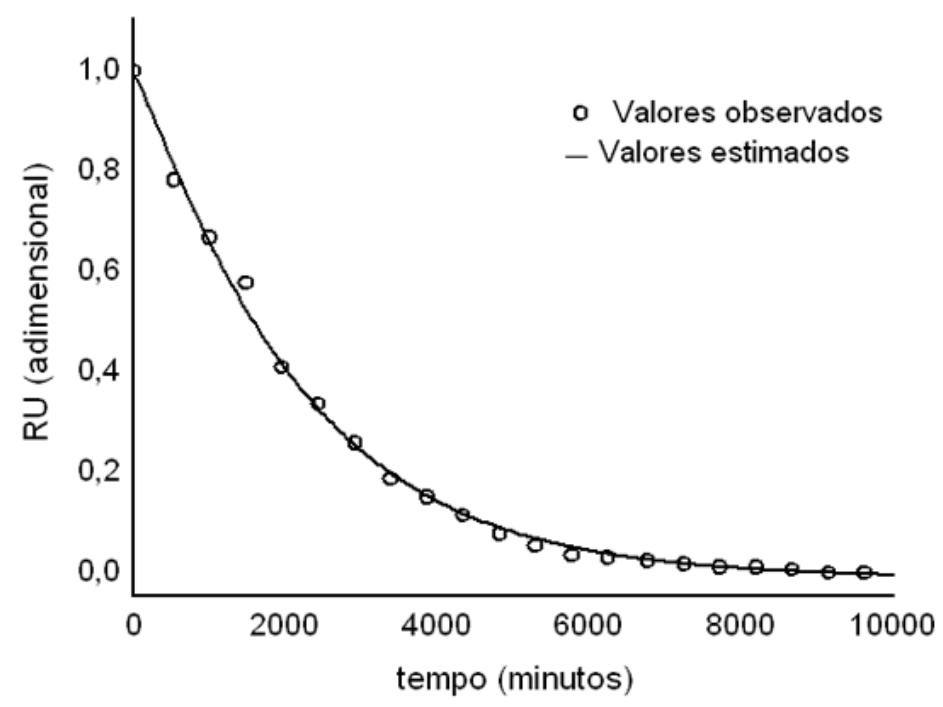

FIGURA 2. Curva de secagem estimada pelo modelo para a secagem com ar ambiente.

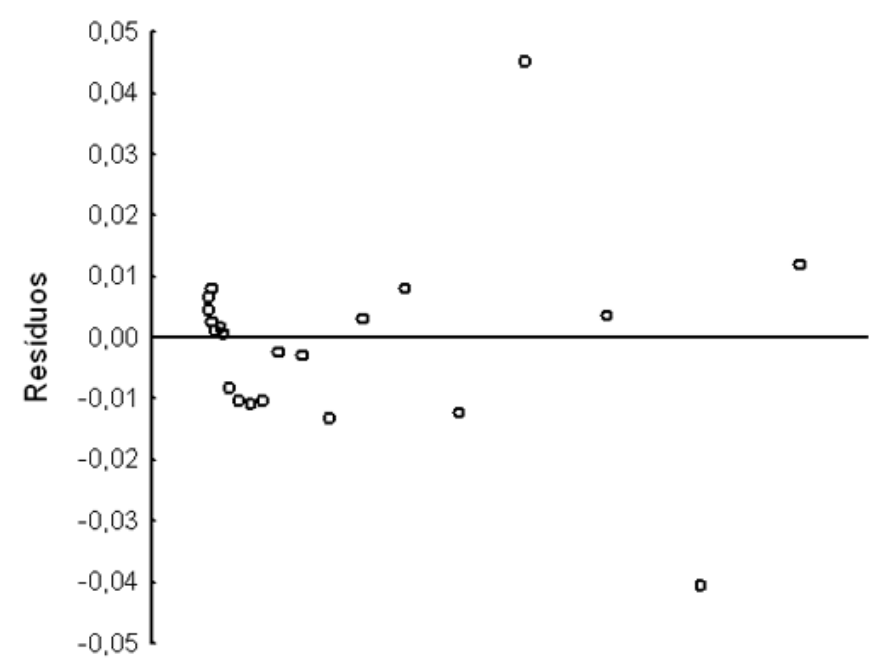

FIGURA 3. Distribuição dos resíduos referentes a secagem com ar ambiente.

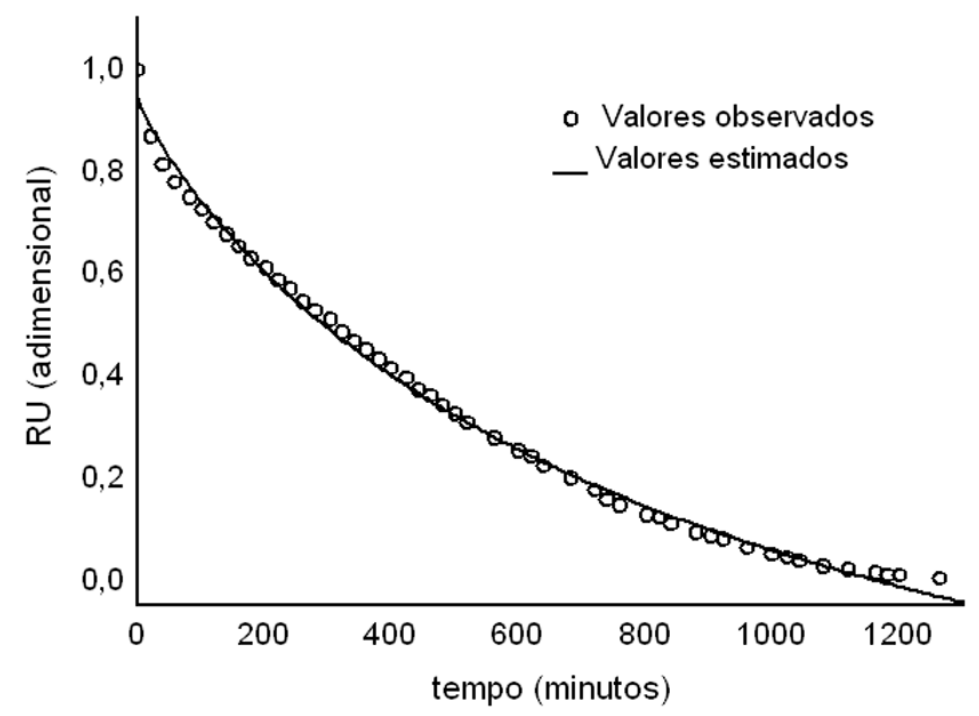

FIGURA 4. Curva de secagem estimada pelo modelo para a secagem com ar aquecido a $40^{\circ} \mathrm{C}$.

Rev. Bras. PI. Med., Campinas, v.16, n.2, supl. I, p.378-387, 2014. 


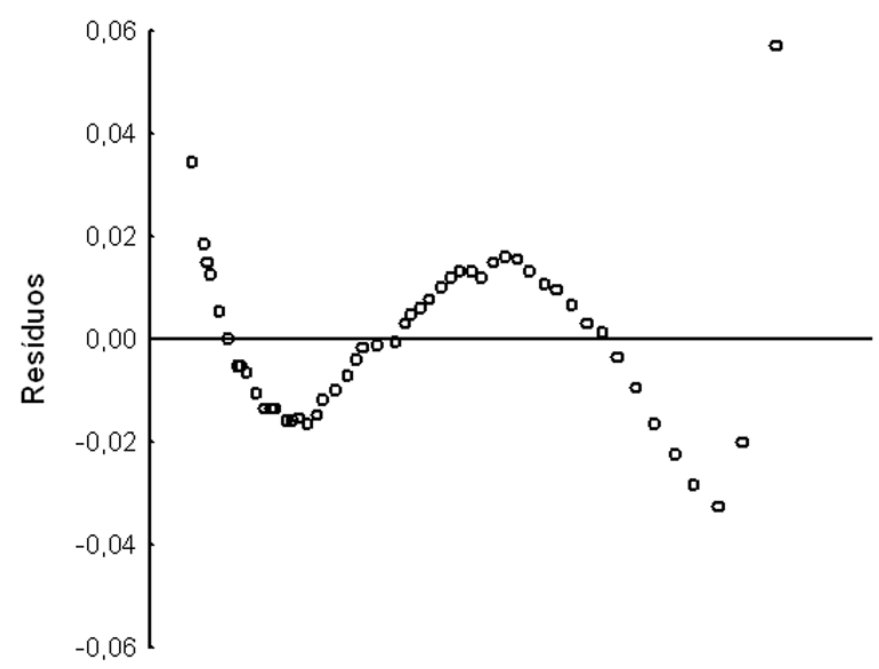

FIGURA 5. Distribuição dos resíduos referentes a secagem com ar aquecido a $40^{\circ} \mathrm{C}$.

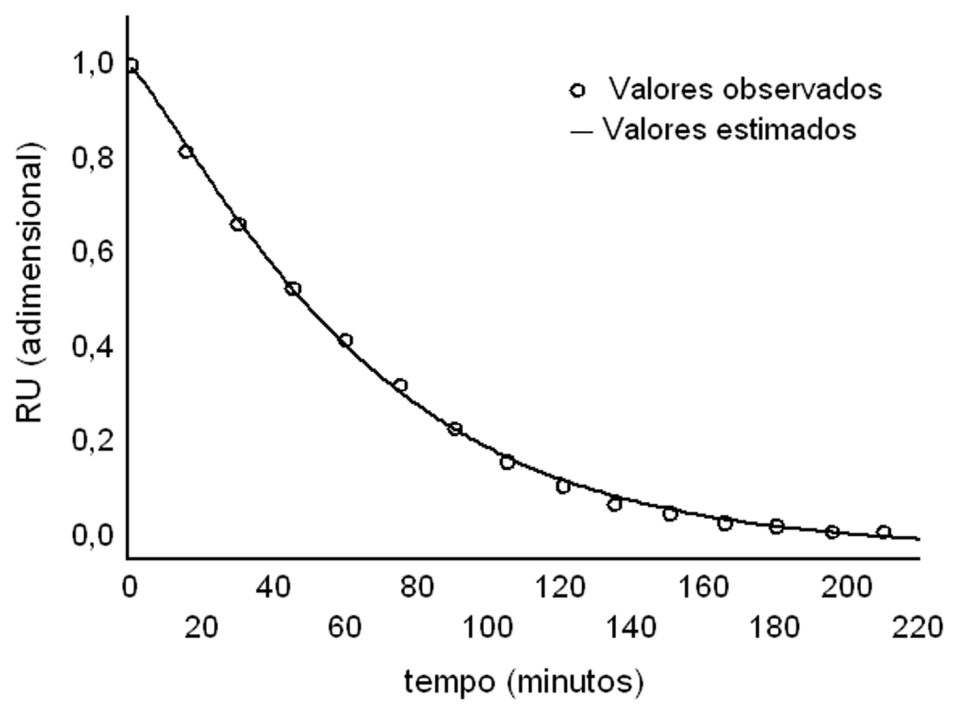

FIGURA 6. Curva de secagem estimada pelo modelo para a secagem com ar aquecido a $50^{\circ} \mathrm{C}$.

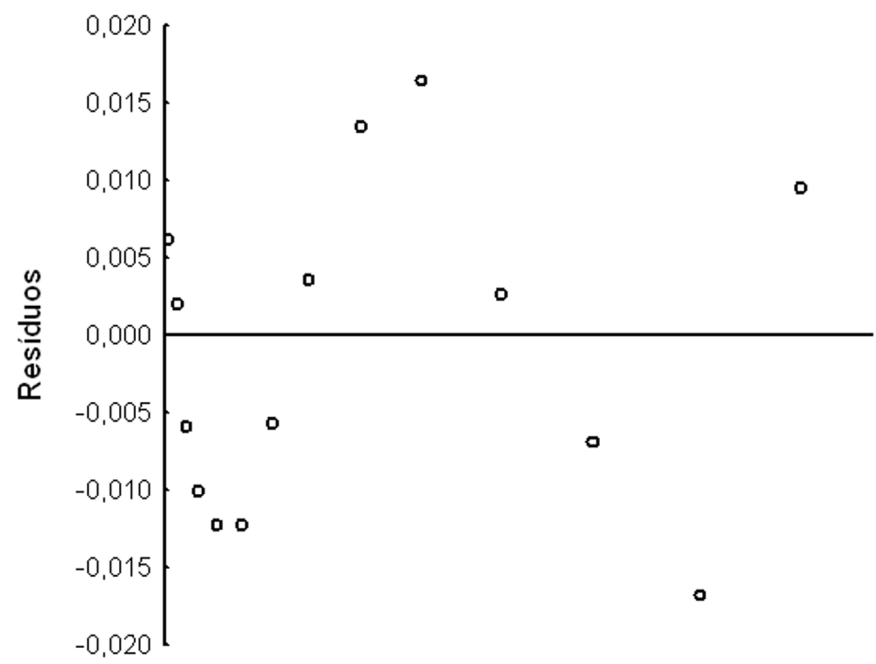

FIGURA 7. Distribuição dos resíduos referentes a secagem com ar aquecido a $50^{\circ} \mathrm{C}$.

Rev. Bras. PI. Med., Campinas, v.16, n.2, supl. I, p.378-387, 2014. 


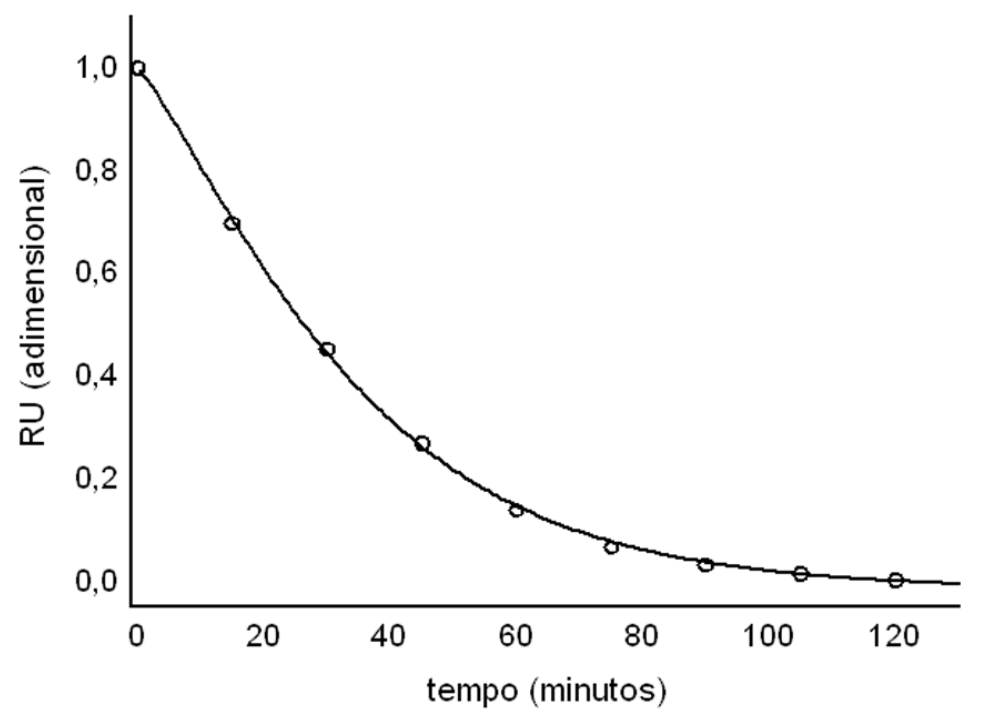

FIGURA 8. Curva de secagem estimada pelo modelo para a secagem com ar aquecido a $60^{\circ} \mathrm{C}$.

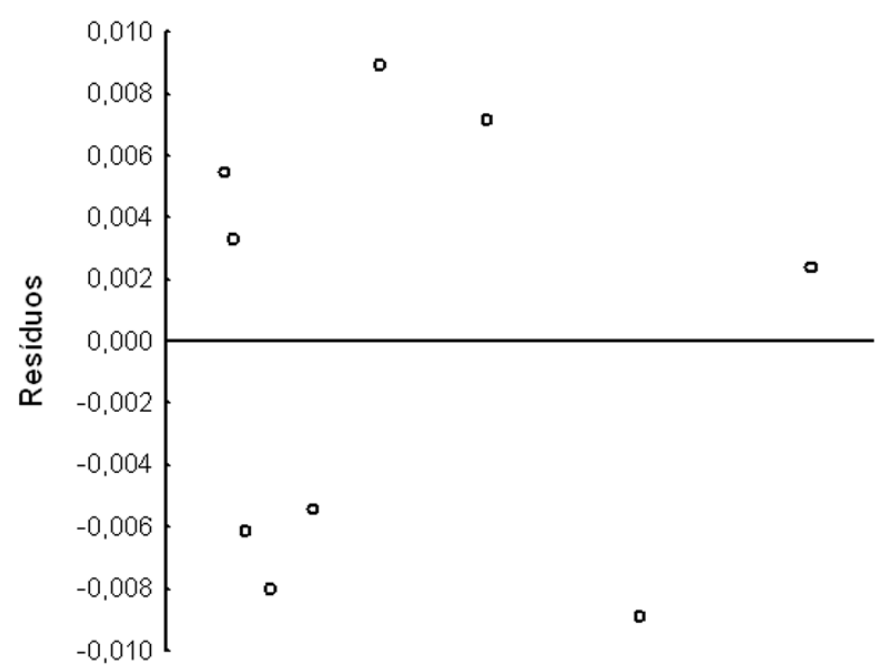

FIGURA 9. Distribuição dos resíduos referentes a secagem com ar aquecido a $60^{\circ} \mathrm{C}$.

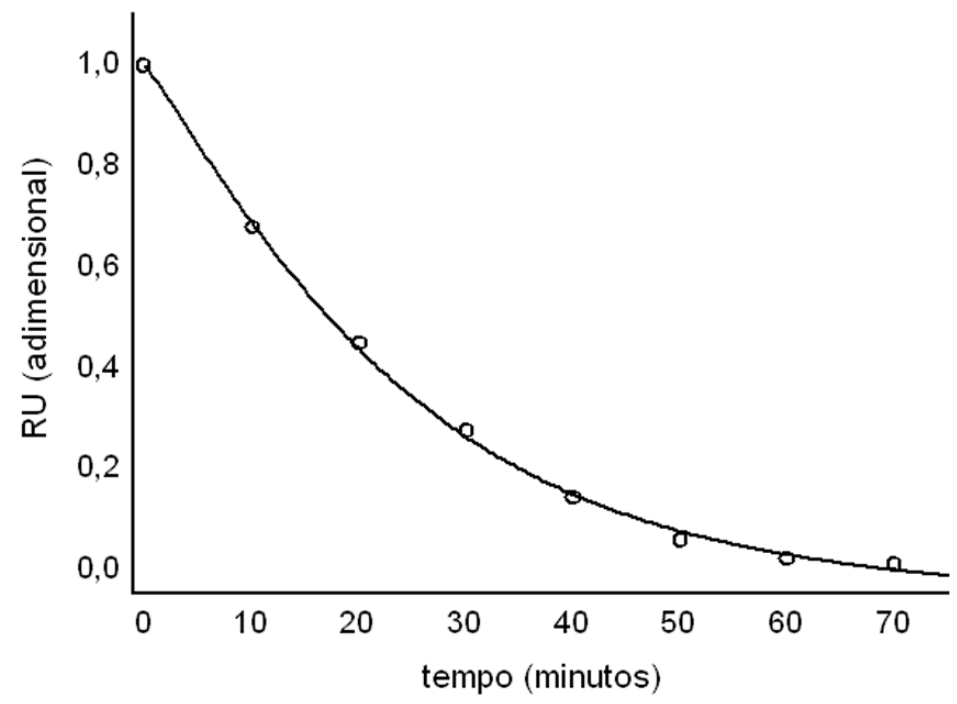

FIGURA 10. Curva de secagem estimada pelo modelo para a secagem com ar aquecido a $70^{\circ} \mathrm{C}$.

Rev. Bras. PI. Med., Campinas, v.16, n.2, supl. I, p.378-387, 2014. 


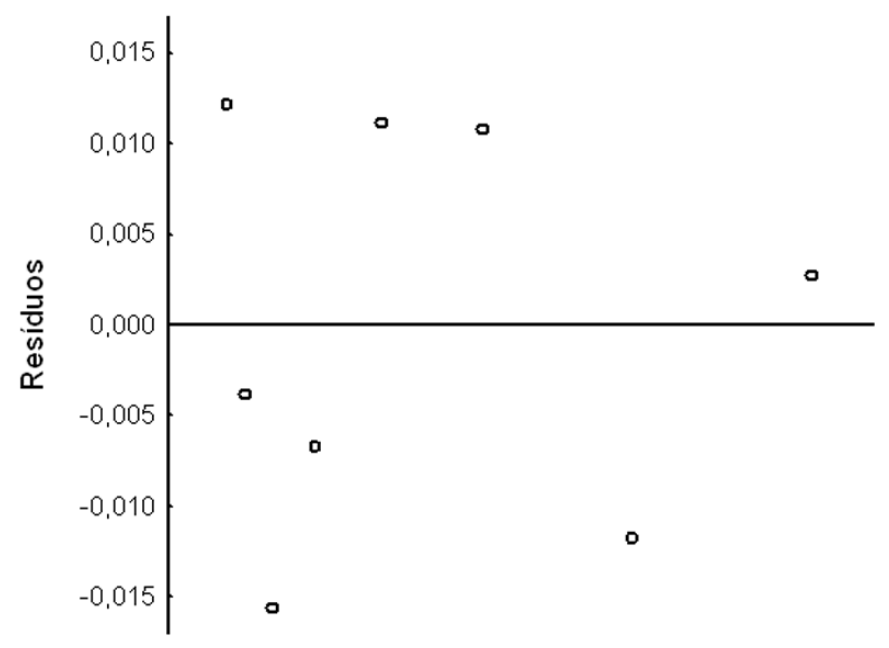

FIGURA 11. Distribuição dos resíduos referentes a secagem com ar aquecido a $70^{\circ} \mathrm{C}$.

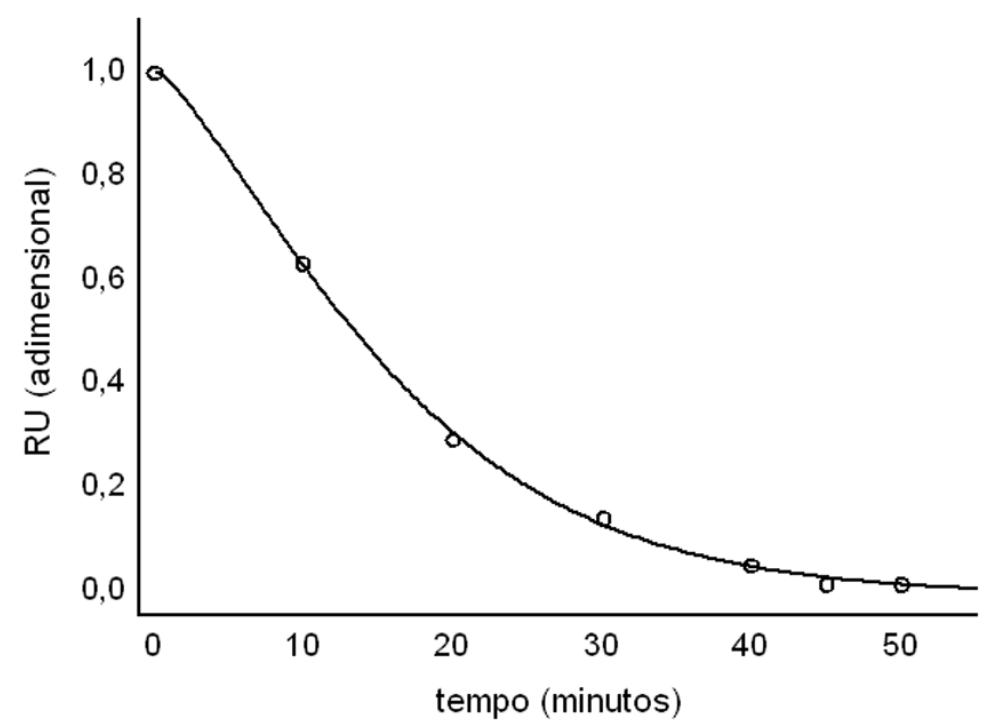

FIGURA 12. Curva de secagem estimada pelo modelo para a secagem com ar aquecido a $80^{\circ} \mathrm{C}$.

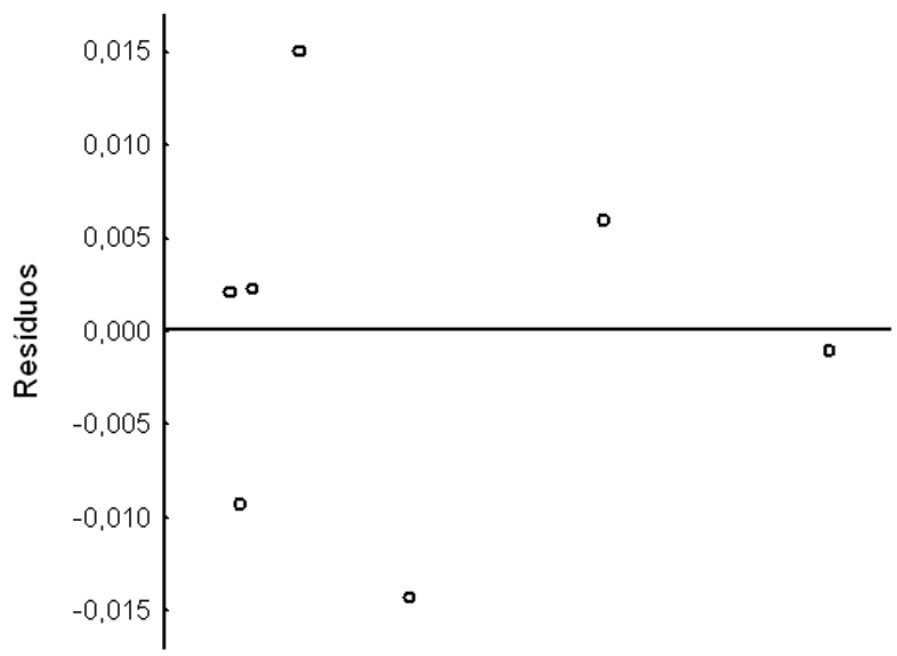

FIGURA 13. Distribuição dos resíduos referentes a secagem com ar aquecido a $80^{\circ} \mathrm{C}$.

Rev. Bras. PI. Med., Campinas, v.16, n.2, supl. I, p.378-387, 2014. 
temperaturas empregadas, visto a maior redução de água foi observada no terço inicial, após reduzindo significativamente a taxa de remoção de água, exceto para a temperatura do ar aquecido a $40^{\circ} \mathrm{C}$, onde não foi observada esta característica, o que justifica a falta de ajuste pelos modelos matemáticos avaliados.

Também se observa que o tempo de secagem com ar ambiente foi de 9600 minutos, e quando aquecido a $40^{\circ} \mathrm{C}$ o tempo foi de 1260 minutos (redução de $86,8 \%$ ), para $50^{\circ} \mathrm{C}$ o tempo foi de 210 minutos (redução $83,3 \%$ em relação a $40^{\circ} \mathrm{C}$ ), para $60^{\circ} \mathrm{C}$ o tempo foi de 120 minutos (redução $42,8 \%$ em relação a $50^{\circ} \mathrm{C}$ ), para $70^{\circ} \mathrm{C}$ o tempo foi de 70 minutos (redução $41,7 \%$ em relação a $60^{\circ} \mathrm{C}$ ), e para $80^{\circ} \mathrm{C}$ o tempo foi de 50 minutos (redução $28,6 \%$ em relação a $70^{\circ} \mathrm{C}$ ). Então, a redução do tempo de secagem decresce com o aumento da temperatura do ar.

\section{CONCLUSÃO}

Nas condições em que foi desenvolvida a pesquisa, pode-se concluir:

O modelo matemático de Midilli et al. pode ser empregado para descrever o processo de secagem de guaco com ar ambiente, e aquecido na faixa de 40 a $80^{\circ} \mathrm{C}$; e

A maior taxa de remoção de água ocorre no terço inicial da secagem.

\section{AGRADECIMENTO}

Os autores agradecem ao CNPq, CAPES e FAPEMIG pelo apoio financeiro, imprescindível para a execução do trabalho.

\section{REFERÊNCIA}

ABIFITO. Fitoterápicos: setor movimenta US\$ 400 milhões no Brasil. Disponível em: <http://www.abifito. com.br>. Acesso em: 27 out. 2003.

ASAE STANDARDS. Standards engineering practices data: moisture measurement-forages, ASAE S358.2 DEC99. St. Joseph: American Society of Agricultural Engineers, 2000. p. 565-72.

BOLINA, R. C.; GARCIA, E. E.; DUARTE, M. G. R. Estudo comparativo da composição química das espécies vegetais Mikania glomerata Sprengel e Mikania laevigata Schultz Bip. ex Baker. Revista brasileira de farmacognosia, v. 19, n. 1b, p. 294-298, 2009.

CORREAA, P.C. et al. Modelo matemático para representação da higroscopicidade de plantas medicinais. Revista Brasileira de Armazenamento, v. 27, n. 1, p. 7-11, 2002.

EVIN, D. Thin layer drying of Gundelia tournefortii L. Food and Bioproducts processing, V.90, n.2, p.323-332, 2012.

GUERRA, M.P; NODARI, R.O. Biodiversidade: aspectos biológicos, geográficos, legais e éticos. In: SIMÕES, C. M. O et al. Farmacognosia: da planta ao medicamento. 5.ed. Porto Alegre/Florianópolis: UFRGS/ UFSC, 2003. p.13-28.

LORENZI, H.; MATOS, F.J.A. Plantas medicinais no Brasil: Nativas e exóticas. Nova Odessa: Instituto Plantarum, 2002. 512p.

LOW, T. et al. Segredos e virtudes das plantas medicinais. 1.ed. Rio de Janeiro: Reader's Digest, 1999. 416p.

MARTINAZZO, A.P.; CORREAA, P.C.; RESENDE, O.; MELO, E.C. Análise e descrição matemática da cinética de secagem de folhas de capim-limão. Revista Brasileira de Engenharia Agrícola e Ambiental, v.11, n.3, p.301-306, 2007.

MELO, E. C.; RADÜNZ, L. L.; MELO, R. C. A. Influência do processo de secagem na qualidade de plantas medicinais - Revisão. Engenharia na Agricultura, v.12, n.4, p. 307-315, 2004.

MIDILLI, A.; KUCUK, H.; YAPAR, Z. A. New model for single-layer drying. Drying Technology, v.20, n.7, p.1503-1513, 2002.

OLIVEIRA, F.;AKISUE, G.; AKISUE, M.K. Farmacognosia. São Paulo: Atheneu,1998. 412p.

MOHAPATRA, D.; RAO, P.S. A thin layer drying model of parboiled wheat. Journal of Food Engineering, v.66, p.513-518, 2005.

PANCHARIYA, P.C.; POPOVIC, D.; SHARMA, A.L. Thinlayer modeling of black tea drying process. Journal of Food Engineering, v.52, n.4, p.349-357, 2002.

PRATES, M. O.; PIZZIOLO, T. A.; TÔRRES, A. G.; MELO, E. C. Modelagem matemática de um sistema de secagem de plantas medicinais e aromáticas. Engenharia na Agricultura, v.15, n.2, p. 96-108, 2007.

PRATES, M.F.O.; REIS, R.C.; DEVILLA, I.A.; FARIA, R.Q.; LIMA JUNIOR, A.F. Cinética de secagem de folhas de Solanum lycocarpum A. St.-Hil. (fruta-de-lobo). Revista Brasileira de Plantas Medicinais, v.14, n.3, p.514-521, 2012.

RADÜNZ, L.L. Efeito da temperatura do ar de secagem no teor e na composição dos óleos essenciais de guaco ( Mikania glomerata Sprengel ) e hortelã-comum (Mentha x Villosa Huds). 2004. 90p. Dissertação (Doutorado - Área de concentração em Engenharia. Agrícola) Departamento de Engenharia agrícola, Universidade Federal de Viçosa, Viçosa.

RADÜNZ, L.L.; AMARAL, A.S.; MOSSI, A.J.; MELO, E.C.; ROCHA, R.P. Avaliação da cinética de secagem de carqueja. Engenharia na Agricultura, v.19, n.1, p.1927, 2011

RAO, V.G. et al. Study of drying characteristics of largecardamon. Biomass \& Bioenergy, v. 20, n.1, p.37-43, 2001.

REIS, R.C.; DEVILLA, I.A.; ASCHERI, D.P.R.; SERVULO, A.C.O.; SOUZA, A.B.M. Cinética de secagem de folhas de manjericão (Ocimus basilicum L.) via infravermelho. Revista Brasileira de Engenharia Agrícola e Ambiental, v.16, n.12, p.1346-1352, 2012.

RESENDE, O.; CORREAA, P.C.; GONELI,A.L.D.; BOTELHO, F.M.; RODRIGUES, S. Modelagem matemática do processo de secagem de duas variedades de feijão (Phaseolus vulgaris L.). Revista Brasileira de Produtos Agroindustriais, v.10, n.1, p.17-26, 2008.

STATISTICA for Windows 6.0. Data analyses software system. Street Tulsa, OK, USA. StatSoft, Inc., 2001.

Rev. Bras. PI. Med., Campinas, v.16, n.2, supl. I, p.378-387, 2014. 